\title{
ENGINEERING EDUCATION IN CANADA IN THE WAKE OF COVID-19 PANDEMIC
}

\author{
A. Hosseini and S. Koohi-Fayegh \\ Department of Mechanical and Manufacturing Engineering, Ontario Tech University, Oshawa, Canada \\ sayyedali.hosseini@ontariotechu.ca
}

\begin{abstract}
In this article, a number of difficulties faced in research, teaching and learning by engineering instructors, researchers, students and administrative staff in the universities in Canada during the COVID-19 pandemic are discussed. A few solutions, such as use of a sample online assessment tool, that might aid in better delivery of engineering courses are provided. The effectiveness of such solutions devised for short-term use and their applicability in the longer-term online teaching are discussed. Special focus is given to engineering education due to the special standards of course delivery and assessment required by the Engineers Canada and Canadian Engineering Accreditation Board.
\end{abstract}

Keywords: Engineering education, graduate attributes, accreditation, COVID-19 pandemic, assessment, academic integrity.

\section{INTRODUCTION}

As the world becomes more interconnected, the likelihood of being impacted by an incident at the other side of the globe increases. The fast spread of COVID-19 is the most recent example of such incident. According to the World Health Organization (WHO), in December 31, 2019 a cluster of cases of pneumonia was reported by Wuhan Municipal Health Commission, in Hubei Province, China. It took only more than two months up until March 11, 2020 when WHO declared COVID-19 a pandemic due to its alarmingly worldwide spread [1]. To contain the COVID-19 pandemic and minimize its health consequences, Government of Canada, similar to many other countries, imposed restrictive measures such as encouraging work from home, prohibiting social gatherings, and closing businesses and schools. These restrictive measures have been proven effective in slowing down the spread and reducing the number of reported cases in highly affected provinces such as Quebec and Ontario. Nevertheless, they have introduced unforeseen challenges and taken a significant toll on people and organizations along with provincial and federal governments.

Aside from its financial, and health consequences, COVID-19 has greatly influenced educational systems globally and Canada has been no exception. Although all disciplines suffered from the pandemic consequences, engineering programs, which are extremely dependent on physical presence and experiential learning, are certainly among the hardest hit. All aspects of engineering education in Canada including teaching, research, and administration have since been severely impacted.

At the teaching level, the new circumstances forced our schools and universities to enter a different world almost overnight by shifting form in-person to online platforms, modifying all course activities that previously required students to work in close physical proximity, reassessing and revising their student grading systems, and yet ensuring the integrity of their exams and other course assessments. At the research level, access to labs and university premises that used to be operational $24 / 7$ were restricted; thus, faculty members and graduate students have started to experience limited access to equipment and facilities. Although universities have started to develop contingency plans for granting controlled access to the labs, such restrictions have negatively affected researchers, more particularly those in early stages of their career. Borders closure and lack of mobility, especially for newly admitted international students, also added to the complexity of the situation. From the administrative perspective, uncertainties about future enrolment, class sizes, providing sufficient IT support, new hiring, and work load are the current issues to dealt with.

\section{COVID-19 VS. OUTCOMES-BASED EDUCATION}

In a broader picture, COVID-19 pandemic affected the accreditation of engineering programs to some extent. In Canada, every engineering program offered by a university must undergo a rigorous accreditation process performed by Engineers Canada. This process promotes continual improvement of engineering education in Canada, and ensures that engineering graduates are academically fit to meet the standards of professional engineering licensing process. This is referred to as outcomes-based education (OBE) system in which the focus is placed on the outcome (knowledge and skills gained by students) rather than input (materials presented and taught to students) [2,3]. 
To achieve an effective outcome-based engineering education system, engineering programs must instill twelve skills, also known as graduate attributes (GAs), in their students [4]. These attributes are deemed as the necessary skills required for the success of engineering graduates in their future engineering careers. Such attributes are achieved by planning modes of teaching and student assessment in engineering courses. First inception of COVID-19 restrictive measures and its impact on such planned teaching and assessment modes raised concerns among Canadian institutions regarding the proper coverage of graduate attributes; especially those that require more student and instructor interaction and physical presence such as "Use of Engineering Tools" and "Team work."

To preserve the appropriate level of quality of course activities that are aimed to arrive at the planned graduate attributes corresponding to the accreditation of the programs, engineering faculties across Canada started to allocate resources to keep the quality of online mode of course delivery as high as possible. The heavy burden felt by engineering faculty members, staff, and students to cope with such a rapid transition has been recognized by the Engineers Canada and Canadian Engineering Accreditation Board (CEAB). Therefore, in collaboration with Engineering Deans Canada (EDC), Accreditation Board Executive Committee identified factors that are expected to impact the accreditation of engineering programs in Canada. According to Engineers Canada, switching course delivery mode requires significant human and financial resources and limitation of these resources due to health concerns may significantly limit the ability of universities in preparing the required accreditation materials that are true representations of the quality of their program. As a result, Engineers Canada and Canadian Engineering Accreditation Board (CEAB) have developed plans such as deferral for the upcoming accreditation visits and extension of the currently accredited programs for one year to relieve this pressure [4].

While all schools in Canada who offer programs during the COVID-19 restrictions have introduced online modes of delivery in their teaching styles, the extent of such delivery varies among schools and/or programs. Some programs might have switched to full online delivery of all lectures, tutorials and laboratories, and others are using a hybrid of online and on-campus delivery. For example, lectures and tutorials might be delivered synchronously online and a revised version of laboratories, allowing fewer students in one room, might be delivered on campus. Such lecture delivery style allows students a learning experience that resembles the one on campus in some aspects, but limits students' exposure to on-campus lab demonstrations. To improve students' engagement and interaction in synchronous lectures, use of online break-out rooms might allow students to share their thoughts on the course topic and interact with their peers and their instructor in a smaller group. Alternatively, asynchronous delivery of lectures and tutorials, where possible, allows scheduling of a larger number of laboratories on campus resulting in students' full exposure to laboratory presentations. However, while it might seem that asynchronous lecture delivery allows students more study time in their schedule and much content can be added to the course, there is a limit to such content addition in the students' limited study time that can indeed result in improved learning outcome. Cognitive fatigue has been shown to be directly associated with university students' reduced academic attainment [5]. The effects of larger course content delivery in an online format on students' cognitive and screen fatigue need to be assessed in more detail before such online content additions are made. Moreover, asynchronous lecture delivery does not offer instructor-student interaction in the same way that on campus or synchronous lectures and tutorials do. This could result in more incidents of cyberbullying, especially in the absence of policies devised to prevent them. Resources need to be made available to the faculty who teach online to create strategies to avoid cyberbullying directed towards them or their students [6]. In addition, there is much training needed for instructors to prepare asynchronous material in creative ways that provide a meaningful learning experience for students in the same way that on-campus lectures and tutorials do. Such style of asynchronous course delivery also requires students to be familiar with use of online technologies and take more responsibility in their own learning experience. Asynchronous course delivery might be beneficial only to those students who are organized and have a high level of time management skills. Use of online tools such as calendar applications might assist with a larger number of students in keeping up with the course teaching pace and delivering assignments, but would still require a higher level of online engagement and organization skills from students. Use of various combinations of online and oncampus delivery modes shows that all such solutions come at a number of costs and perhaps a number of benefits, to the instructor, the student or both, when compared to oncampus delivery [7-9].

From the students' perspective, online course delivery offers them flexibility in reviewing the course content at any time and from any location. With no limits on accessing the course contents, students with various learning abilities can adjust the number of times they review instructor lectures to their learning pace. In addition, the anonymity that can be offered to students in online discussions could encourage more participation in discussions, and the time flexibility of online discussions could allow participation by students who need more time to form thoughts.

Despite the flexibility offered by asynchronous mode of delivery, especially in the online format, it introduces new challenges and could intensify the already-existing issues. Implementation of technologies and provision of adequate technical support to students and the instructors are among 
the newly introduced challenges while increased workload, potential loss of academic freedom, and possibility of unfavorable teaching evaluation are among the currently existing issues [3]. Implementing new technologies in online learning such as using software for recording lectures and editing videos along with development of student assessment methods such as assignments and exams in an online format are extremely time consuming and labor intensive. Use of more frequent testing to spread out the marks among deliverables and prevent students' massed practice strategies has already been shown to be effective in enhancing learning in a normal setting [10], but it might become particularly beneficial in the online teaching environment as well. In addition, such assessments must be reliable enough from academic integrity and accreditation perspective. Developing such assessments increases the workload of faculty members who have already been overwhelmed with graduate students' supervision, research activities, teaching commitments, and administrative responsibilities and in turn results in push back. Collection and analysis of graduate attribute assessment data, which was already regarded as a bureaucratic and externally imposed task [2, 11] will be more problematic during the pandemic due to the online mode of delivery and remote assessment. As a result, having access to reliable course assessment tools that report student performance data automatically is considered a great asset both for protecting the academic integrity and for exporting data for accreditation purposes.

In the next two sections, a sample online assessment tool is introduced and preliminary results of the impact of use of this tool on students' performance are analyzed to show some of the benefits of such online tools as well as considerations that must be accounted for when using them. Note that this case study presentation is not to serve as the basis for promotion of using this tool, but is rather presented to support the arguments previously mentioned; namely, labour-intensiveness of use of online tools as well as uncertainty in their effectiveness in addressing the graduate attributes of Canadian engineering courses. Providing instructions on how to use this tool, its advantages, and disadvantages is beyond of the scope of the present study. Details can be found in [12].

\section{CASE STUDY: ONLINE ASSESSMENT AND GRADUATE ATTRIBUTES}

Traditionally, engineering students are given a number of questions to complete independently during paper-based exams in order to demonstrate their problem-solving skills in a proctored environment. Online exams with no inperson proctoring might jeopardize the integrity of assessment. Thus, proper planning along with strict online monitoring is crucial to ensure the highest standards are met for assessing students remotely. Tools such as
Respondus Monitor and Proctor Track are currently being used in some Canadian institutions.

In the past two years and even before the pandemic hit, the first author and his team were involved in developing a streamlined online assessment system for Manufacturing and Production Processes, a 3rd year course for Automotive, Manufacturing, and Mechanical Engineering students at Ontario Tech University. The developed system is built using Numbas [13], an open educational resource. The project was initially aimed at promoting student learning, reducing grading time, and promoting academic integrity in engineering courses. However, inception of COVID-19 proved usefulness of such a system beyond the projected scope. Figure 1 shows the user interface of the online assessment system for multiple choice questions and problems. The objective was to evaluate both knowledge and problem-solving skills graduate attributes.

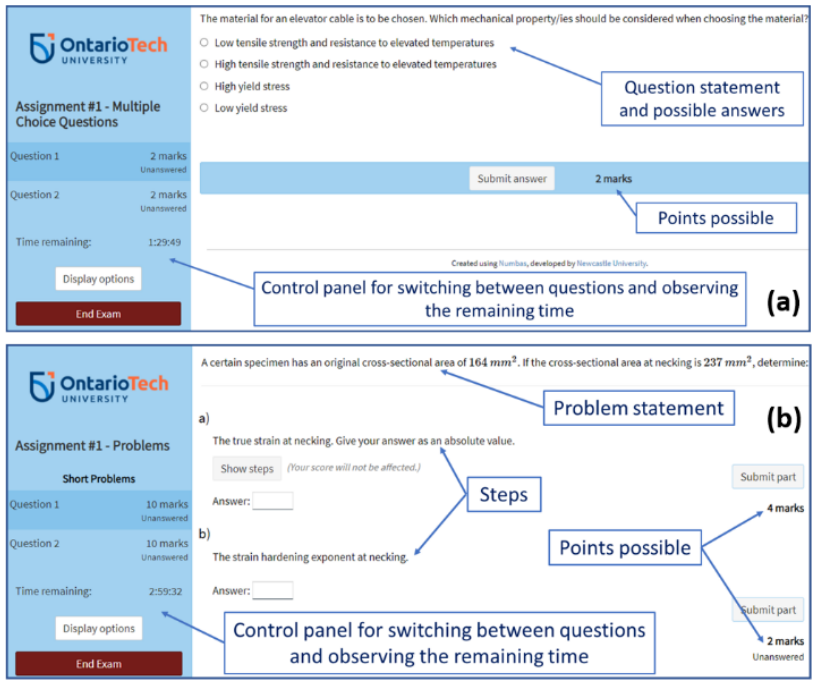

Fig. 1. User interface of the online assessment for (a) knowledge-based questions and (b) problems

The developed online assignment system allows generating different versions of knowledge-based questions and problems for each student, guiding them through the problem-solving process, allowing them to receive part marks for providing solutions to intermediate steps, especially for longer, more complex problems, and finally, marking assignments accurately in real-time and providing immediate feedback to students. In addition, such a tool offers more flexibility in terms of delivery and marking and provides the instructor with statistical data such as number of attempts each student has made (in case more than one attempt is allowed) and when each attempt has started and ended.

In transition to online teaching and assessment, use of statistical tools to analyze student performance data becomes important. The statistical data enables the instructor to acquire a better understanding of students' habits and coordinate their teaching style accordingly to aid 
in their students' learning experience. However, initial development of such systems is labor-intensive and requires financial resources to allow training and technical support to assist users. The post-assessment tool in Numbas can be adopted for other engineering courses and can be implemented for variety of course assessment components depending on the graduate attribute to be evaluated. Figures 2 and 3 show the features of instructor dashboard and a sample of exported data, respectively.

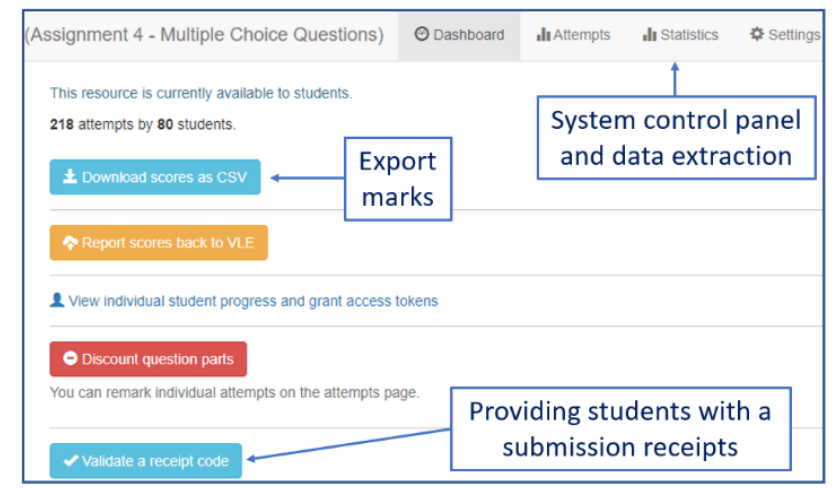

Fig. 2. Instructor dashboard of the online assignment system for controlling the parameters and exporting data

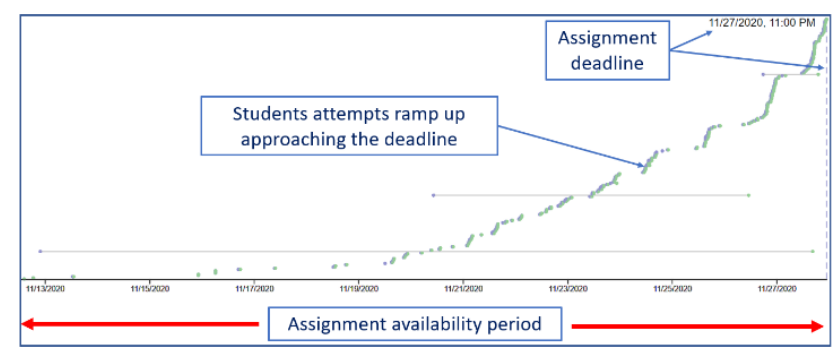

Fig. 3. Sample of data showing students' attempt time

However, while the post-assessment tools such as the one in Numbas offer an effective way to analyze students' behaviour, a more detailed analysis on factors beyond attendance and/or participation or one that would allow assessment of specific GAs in engineering courses might require designing new statistical variables.

\section{ANALYZING THE EFFICACY OF THE ONLINE ASSESSMENT SYSTEM}

To analyze the efficacy of the online assessment system, students' performance in knowledge-base and problem solving, as two graduate attributes of concern, was compared between fall 2017 and 2020 course offerings. In 2017, students in Manufacturing and Production Processes received only paper-based assignments, whereas in 2020, students in the same course received only online assignments. The corresponding author was responsible for teaching this course in both years using same course material. In 2017, class materials were delivered in-class and in 2020 they were delivered online synchronously due to the COVID-19 pandemic. Figure 4 presents the percentage of students in each performance level (for KB) defined by CEAB. The levels include exceeds expectation (if the mark obtained by student for the assessment corresponds to that $\mathrm{GA} \geq 80 \%$, level 3 ), adequately meets $(60-80 \%$, level 2$)$, minimally meets $(50-60 \%$, level 1$)$, and fails to meet $(<50 \%$, level 0$)$.

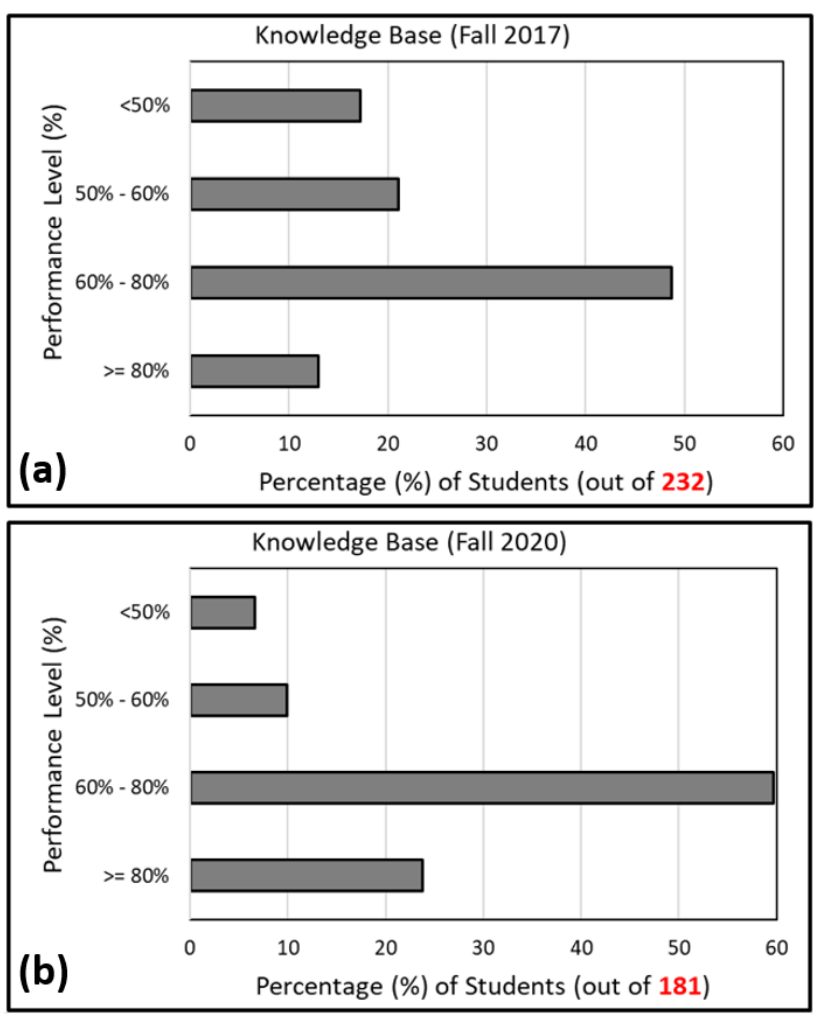

Fig. 4. Students' performance in knowledge base GA (a) Fall 2017 and (b) Fall 2020

As can be seen in figure 4, combined percentage of students in levels 3 and 2 increased from around $60 \%$ in 2017 to more than $80 \%$ in 2020 despite the COVID-19 pandemic and its impact on both instructors (e.g., change in delivery mode) and students (e.g., possibly their mental health). This can be attributed to the fact that students who used online system of assessment in 2020 were exposed to more $\mathrm{KB}$ questions and thus practiced more compared to those who wrote paper-based assessments in 2017.

Figure 5 presents the percentage of students in each performance level for problem analysis GA. As can be observed, there was no significant change in students' performance in problem analysis GA which was rather surprising. It was expected that the students using online systems of assessment perform better in problem analysis due to having the chance of trying various questions is multiple trials. The same result was also noticed in use of same-question format and a variable one in Numbas in student performance assessment of problem-solving assignments in a third-year Mechanical Engineering 
course, Heat Transfer, offered in Winter 2020 and 2021, respectively. This observation requires more investigation; however, studies in open literature report that exposing students that to online assignments do not necessarily yield better assessment result $[14,15]$. While the final outcome was not significantly improved using Numbas, the effect of using this tool on the level of students' efforts would need to be assessed to draw better conclusions on the usefulness of this online assessment tool.

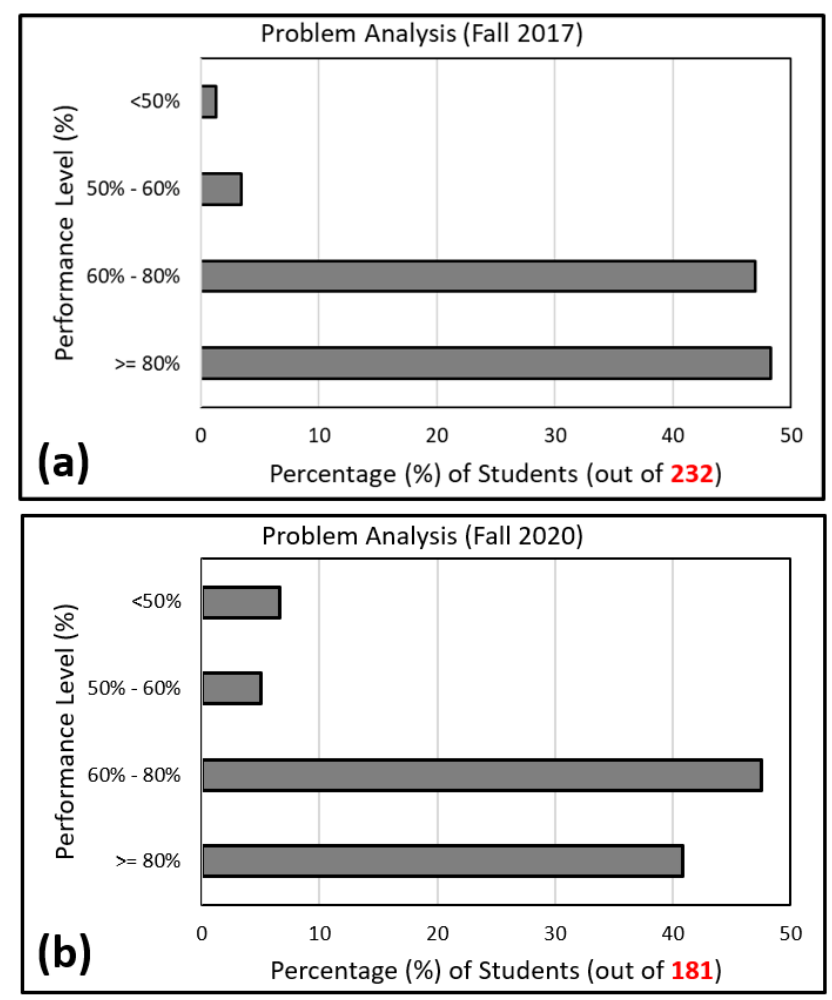

Fig. 5. Students' performance in problem analysis GA (a) Fall 2017 and (b) Fall 2020

Numbas is a sample online assessment tool that has proved effective in assessment of GAs such as students' course knowledge and problem-solving skills. Graduate attributes such as communication and team works have also been met in the online setting in many engineering courses by students' using online communication and collaboration tools. Adolphe et al. [16] suggests messaging platforms such as Slack as effective tools that can aid optimization of engineering design, communication, and collaboration in an online setting. Nevertheless, it might not be as effective in assessing GAs such as design and/or investigation involving hand-on and laboratory work. Such GAs are more complicated to assess using online tools. Virtual labs have been used in some disciplines including engineering [17] and their advantages such as lowering the risk involved in real experimentation, letting students to explore unobservable phenomena, allowing multiple experiments and potentially lowering budget requirements have been discussed [18, 19]. Budhu [17] suggests that such labs can deliver the same level of learning outcomes as real labs if properly designed to match a real setting as closely as possible. To achieve such goal, Vergara et al [20] recommend use of virtual reality as the best option. Jong et al [19] suggest that in promotion of conceptual understanding, virtual labs might have more advantages to offer, but in instilling excitement of hands-on activities in students, virtual labs lag behind physical labs. They suggest that a combination of virtual and physical labs may offer advantages that neither lab mode do. While use of virtual labs can be useful under COVID-19 period when universities have been urgently adapting to the new restrictions, research is still needed to support the potential of using such labs after the pandemic in delivering GAs related to investigation in engineering disciplines. If proved useful, interdisciplinary teams involving subject experts, technologists, learning specialists, data scientists, etc. are needed to develop and maintain such labs and ultimately training is needed to teach them effectively. Currently, it does not seem that such online tools exist for several engineering courses that can assess investigation graduate attribute without compromising the quality of assessment and engineering students' learning outcomes.

\section{CONCLUSIONS AND RECOMMENDATIONS}

In this paper, some of the advantages and disadvantages of online teaching methods used in the universities in Canada during the COVID-19 pandemic were discussed and criticized. A few solutions that might aid in better teaching engineering courses and lessons learned from use of a sample online assessment tool, Numbas, that can be used in some engineering courses are shared. Some of the aforementioned disadvantages of online teaching can be avoided in time and with improved planning. Issues such as lack of training for effective and creative online course delivery and in such a short time during COVID-19 restrictions can be overcome in time if schools plan to provide such training to instructors in future years and account for the workload that such training and transition might require. In the absence of the pandemic, online assessment tools such as Numbas can be used and exams can be scheduled on campus to avoid issues that arise with integrity of online assessments. Asynchronous course offerings for part of the courses allows schools more flexibility to include a deeper coverage of hand-on and laboratory work in students' schedule on campus. However, some of the issues related to online delivery of engineering courses would still remain even after sufficient time has passed and the pandemic is over. Engineering instructors would still face difficulties in meeting quality standards set by CEAB that are set based on on-campus delivery of engineering courses. Activities requiring students to take part in group work or those related to working on laboratory experiments and building design prototypes are all essential components of engineering 
education and serve important objectives in students learning experience. Without the health risks posed by COVID-19, it is difficult to justify their replacement by online tools. Overall, COVID-19 has posed unprecedented circumstances to faculty members in managing research and in teaching engineering courses, and to students in their learning experience. It does not appear that there could be any online alternative for conducting research on campus. As for teaching, more analysis is needed to understand the benefits and drawbacks of employing online tools. The students and instructors are facing the direct impacts of such transition and seem to be the most appropriate groups to provide feedback and take part in such analysis to find optimum solutions for improved delivery of engineering courses in the future.

\section{Acknowledgements}

The authors acknowledged the financial support provided by the Ontario Tech University through Students Success Innovation Fund (SSIF). Technical recommendations and supports provided by Dr. Caroline Ferguson, faculty development officer at Ontario Tech University Teaching and Learning Center, is also greatly appreciated.

\section{References}

1. World Health Organization. 2021 [cited 2021 3/5/2021]; Available from: https://www.who.int/.

2. A.M. Parker, E. Watson, M. Ivey, and J.P. Carey, Approaches to graduate attributes and continual improvement processes in faculties of engineering across Canada: A narrative review of the literature. Proceedings of the Canadian Engineering Education Association (CEEA), 2019.

3. A. Parker, N. Dyck, and J. Carey, An online resource hub for engineering faculty: providing practical information and support for outcomes-based education. Proceedings of the Canadian Engineering Education Association (CEEA), 2020.

4. Accreditation. Engineers Canada. 2021 [cited 2021 3/5/2021]; Available from:

https://engineerscanada.ca/accreditation/aboutaccreditation.

5. A.P. Smith, Cognitive fatigue and the well-being and academic attainment of university students. Journal of Education, Society and Behavioral Science., 2018.

6. J. Raditch, Teaching Online and Cyberbullying: Examining Higher Education Cyberbullying Policies In The Florida State University System. 2019.

7. R. Panigrahi, P.R. Srivastava, and D. Sharma, Online learning: Adoption, continuance, and learning outcome - A review of literature. International Journal of Information Management, 2018. 43: p. 1-14.

8. S. Choudhury and S. Pattnaik, Emerging themes in elearning: a review from the stakeholders' perspective. Computers \& Education, 2020. 144: p. 103657.

CEEA-ACEG21; Paper 158

University of Prince Edward Island; June 21 - 23, 2021- 6 of 6 -
9. Y. Wang, J. Ma, G.E. Kremer, and K.L. Jackson, An investigation of effectiveness differences between inclass and online learning: an engineering drawing case study. International Journal on Interactive Design and Manufacturing (IJIDeM), 2019. 13(1): p. 89-98.

10. J.W. Morphew, M. Silva, G. Herman, and M. West, Frequent mastery testing with second-chance exams leads to enhanced student learning in undergraduate engineering. Applied Cognitive Psychology, 2020. 34(1): p. 168-181.

11. T.W. Banta and C. Blaich, Closing the assessment loop. Change: The Magazine of Higher Learning, 2010. 43(1): p. 22-27.

12. A. Hosseini and C. Ferguson, Use of Numbas as an online assignment system to enhance student learning for problem-based courses, in Technology Tools for Teaching in Higher Education, The Practical Handbook Series. 2020, eCampusOntario: Open Library Pressbooks https://ecampusontario.pressbooks.pub/techtoolsfortea ching/.

13. Numbas. Numbas, really versatile maths e-assessment. 2021 [cited $20213 / 5 / 2021$ ]; Available from: https://www.numbas.org.uk/.

14. T. Gok, Comparison of student performance using web-and paper-based homework in large enrollment introductory physics courses. International Journal of Physical Sciences, 2011. 6(15): p. 3778-3784.

15. A. Williams, Online homework vs. traditional homework: Statistics anxiety and self-efficacy in an educational statistics course. Technology Innovations in Statistics Education, 2012. 6(1).

16. L. Adolphe, G.D. Van de Zande, D. Wallace, and A. Olechowski. Analysis of Virtual Communication Within Engineering Design Teams and its Impact on Team Effectiveness. in ASME 2020 International Design Engineering Technical Conferences and Computers and Information in Engineering Conference. 2020. American Society of Mechanical Engineers Digital Collection.

17. M. Budhu. Virtual laboratories for engineering education. in International conference on engineering education. 2002. Citeseer.

18. S. Ray and S. Srivastava, Virtualization of science education: a lesson from the COVID-19 pandemic. Journal of proteins and proteomics, 2020. 11: p. 77-80.

19. T. De Jong, M.C. Linn, and Z.C. Zacharia, Physical and virtual laboratories in science and engineering education. Science, 2013. 340(6130): p. 305-308.

20. D. Vergara, J. Extremera, M.P. Rubio, and L.P. Dávila, The proliferation of virtual laboratories in educational fields. ADCAIJ: Advances in Distributed Computing and Artificial Intelligence Journal, 2020. 9(1): p. 85-97. 